\title{
Integrative analysis of copy number and gene expression in breast cancer using formalin-fixed paraffin-embedded core biopsy tissue: a feasibility study
}

Mahesh Iddawela ${ }^{1,2,3,4,5^{*}}$, Oscar Rueda ${ }^{1}$, Jenny Eremin ${ }^{6,7}$, Oleg Eremin ${ }^{6,7}$, Jed Cowley ${ }^{8}$, Helena M. Earl ${ }^{1,2,3}$ and Carlos Caldas ${ }^{1,2,3}$

\begin{abstract}
Background: An absence of reliable molecular markers has hampered individualised breast cancer treatments, and a major limitation for translational research is the lack of fresh tissue. There are, however, abundant banks of formalinfixed paraffin-embedded (FFPE) tissue. This study evaluated two platforms available for the analysis of DNA copy number and gene expression using FFPE samples.

Methods: The cDNA-mediated annealing, selection, extension, and ligation assay (DASL ${ }^{\mathrm{TM}}$ ) has been developed for gene expression analysis and the Molecular Inversion Probes assay $\left(\right.$ Oncoscan ${ }^{\mathrm{TM}}{ }^{\mathrm{M}}$, were used for copy number analysis using FFPE tissues. Gene expression and copy number were evaluated in core-biopsy samples from patients with breast cancer undergoing neoadjuvant chemotherapy (NAC).

Results: Forty-three core-biopsies were evaluated and characteristic copy number changes in breast cancers, gains in $1 q, 8 q, 11 q, 17 q$ and $20 q$ and losses in $6 q, 8 p, 13 q$ and 16q, were confirmed. Regions that frequently exhibited gains in tumours showing a pathological complete response (pCR) to NAC were $1 q(55 \%), 8 q(40 \%)$ and $17 q(40 \%)$, whereas $11 q 11$ (37\%) gain was the most frequent change in non-pCR tumours. Gains associated with poor survival were 11q13 (62\%), 8q24 (54\%) and 20q (47\%). Gene expression assessed by DASL correlated with immunohistochemistry (IHC) analysis for oestrogen receptor (ER) [area under the curve $(A \cup C)=0.95$ ], progesterone receptor $(P R)(A \cup C=0.90)$ and human epidermal growth factor type-2 receptor (HER-2) (AUC $=0.96)$. Differential expression analysis between ER+ and ER- cancers identified over-expression of TTF1, LAF-4 and C-MYB ( $p \leq 0.05)$, and between $\mathrm{pCR}$ vs non-pCRs, over-expression of CXCL9, AREG, B-MYB and under-expression of ABCG2.
\end{abstract}

Conclusion: This study was an integrative analysis of copy number and gene expression using FFPE core biopsies and showed that molecular marker data from FFPE tissues were consistent with those in previous studies using fresh-frozen samples. FFPE tissue can provide reliable information and will be a useful tool in molecular marker studies.

Trial Registration: Trial registration number ISRCTN09184069 and registered retrospectively on 02/06/2010.

Keywords: Gene Expression, Copy Number, FFPE, Genomics, Breast Cancer, DASL, Molecular Inversion Probes Assay, Oncoscan Array, Molecular Markers

\footnotetext{
* Correspondence: mahesh.iddawela@monash.edu

${ }^{1}$ Cancer Research UK Cambridge Institute, Li Ka Shing Centre, Robinson Way, Cambridge CB2 ORE, UK

2Department of Oncology, University of Cambridge, Addenbrooke's Hospital,

Hills Road, Cambridge, UK

Full list of author information is available at the end of the article
} 


\section{Background}

Breast cancer remains a major public health problem in the western world, with a significant impact on mortality and morbidity. Despite the considerable amount of research that has been carried out, oestrogen receptor (ER), progesterone receptor (PR) and human epidermal growth factor receptor 2 (HER-2) remain the only routinely used molecular markers in breast cancer [1, 2]. Multiplex markers are being introduced for particular clinical situation but these are currently expensive and not universally helpful $[3,4]$. Breast cancer is a heterogeneous disease and large numbers of samples are needed to reliably characterise different subtypes with confidence $[5,6]$. Unfortunately, availability of FF (fresh frozen) tissues for translational research are limited. However, on the other hand, abundant supplies of FFPE (formalin-fixed paraffinembedded) tissues are readily available for use, provided suitable assays are in place [7] .

One of the main problems associated with FFPE samples is that cellular RNA is degraded and therefore the platforms must be adapted for analysis; this is one of the challenges of using FFPE samples. Standard microarrays used for FF samples are not suitable for analysis of FFPE samples because conventional in-vitro transcription is not amenable to analysis of degraded samples [8].

Two main technologies are employed for gene expression profiling using FFPE tissue: expression microarrays using oligo-(dT) priming (Affymetrix and other custommade microarrays) and a combination of oligo-(dT)/random hexamers together with gene-specific primers utilised by the cDNA-mediated annealing, selection, extension and ligation (DASL) assay $[9,10]$. In the DASL assay, the expression of 502 genes is assessed, each using three primers. Only a $40 \mathrm{bp}$ sequence is required to determine mRNA abundance, and hence this method is generally suitable for the analysis of degraded FFPE samples [11]. Both of these platforms have been used for gene expression profiling of FFPE core biopsy tissues. Bibikova et al. showed that the DASL platform can be used to assess gene expression profiles and evaluate differentially-expressed genes in cancerous and normal tissues [11]. Furthermore, we have shown reliable expression profiles can be generated using FFPE tissue with profiles overlapping with those from FF tissues [12]. DASL has been used to generate signatures of molecular markers associated with poor outcome in prostate cancer [13], genes associated with poor outcome in melanoma [14], and in oesophageal cancer [15].

Copy number alterations may have profound effects on cancer development, and on progression and response to treatment. Thus, characterisation of pivotal changes and their molecular pathways in breast cancer may have important clinical implications. Several welldefined copy number alterations have been identified in cancer, such as ERBB2 in breast cancer [16], N-MYC in neuroblastoma [17, 18] and EGFR-1 in head and neck tumours and gliomas [19-21], which have prognostic as well as predictive implications.

Until recently, there has been uncertainty about the value of FFPE tissue in clinical prognostic marker studies because of technical problems such as difficulties in DNA extraction, low quantities of extractable DNA, and the problems associated with using such DNA owing to degradation. Technological advances in DNA extraction protocols and platforms used for genome-wide copy number analysis (CNA) using DNA extracted from FFPE tissue have progressed rapidly over the past few years $[22,23]$. Newer platforms used for CNA require less DNA, rendering analysis of FFPE material a more realistic and reliable technique.

The Molecular Inversion Probe (MIP) assay is a very promising platform for CNA in both FF and FFPE material $[24,25]$. Degraded DNA can be used in this assay as it only requires a 40-bp sequence for $\mathrm{CNA}$, making it suitable for DNA analysis of FFPE material. This technique has been used to define new copy number changes in Ewing's sarcomas and in childhood leukaemias [26, 27]. The reliability of this method has also been assessed using samples obtained from several institutions. These data suggest that this technology will be a useful tool for CNA using FFPE tissue, and the low DNA requirement renders it ideal for analysis of core biopsies of samples or in situations where only limited material is available.

Integrative analysis of both copy number and gene expression has been shown to be a valuable method for identifying new molecular markers in cancer. In one of the largest studies in breast cancer, Curtis et al. showed that breast cancer can be divided into 10 subtypes using integrative analysis [5]. Chin et al. further showed that novel ER-negative breast cancers can be identified using analysis of gene expression and copy number [28]. If such analysis can be carried out on FFPE tissue, it will enable the evaluation of larger numbers of clinical samples and so lead to faster progress in translational research [29]. This potential has a role in the discovery, as well as the validation, of potential prognostic markers, and as the samples are readily available it is a useful source of material for translational research.

The previous study looked a the role of FFPE analysis using the whole genome DASL assay and its role in gene expression profiling of fresh and FFPE tissue [12].

In this study, profiling of copy number changes and gene expression was carried out using the same FFPE clinical samples. Routinely collected core biopsies were used, to evaluate whether these assays can be used for molecular marker studies. This study used the DASL Cancer Panel Assay to evaluate the FFPE samples. To the best of our knowledge this is the first genome-wide 
copy number and expression profiling study using FFPE core biopsies from patients with large breast cancers undergoing neoadjuvant chemotherapy (NAC).

\section{Methods \\ Samples}

In this study, 63 samples from patients with large locally advanced breast cancer (LLABC) (T2 $>3 \mathrm{~cm}$, T3 or 4 , $\mathrm{N} 1,2)$ treated with NAC trial were used. The trial to evaluate the safety and efficacy of weekly vs. 3 weekly docetaxel $\left(33.3 \mathrm{mg} / \mathrm{m}^{2}\right.$ or $\left.100 \mathrm{mg} / \mathrm{m}^{2}\right)$ administration after 3 weekly Adriamycin $\left(60 \mathrm{mg} / \mathrm{m}^{2}\right)$ and cyclophosphamide $\left(100 \mathrm{mg} / \mathrm{m}^{2}\right)$ for patients diagnosed with LLABC in the period 1999-2002. All patients underwent surgery 4 weeks post NAC, and a core biopsy was performed in all patients prior to starting treatment and patients consented to enter the neoadjuvant study. Following ethical approval, samples from these patients were used for gene expression profiling and CNA. Matched normal and tumour tissue taken at the time of surgery were also used in this cohort.

The copy number analysis was undertaken using both pre-NAC and normal tissues while gene expression was only undertaken with pre-NAC samples only. The study used core biopsy tumour tissue to evaluate these platforms as this is the most readily available sample. Expression analysis was undertaken using multiple replicates. While for copy number analysis, both normal and cancer tissues were used. The samples were evaluated for ER, PR and HER-2 expression using IHC. The ER and PR were reported as positive and negative and HER-2 expression reported as 0 \& 1 (no expression), 2 (equivocal) and 3 (overexpressed).

\section{DNA extraction}

Ten $10 \mu \mathrm{m}$ sections from FFPE blocks were deparaffinised with xylene, and DNA was extracted using the Qiagen DNeasy Tissue kit (Qiagen) according to the manufacturer's protocol with several modifications. The modifications included an initial incubation at $95{ }^{\circ} \mathrm{C}$ for $15 \mathrm{~min}$ (mins) in RTL buffer, followed by 5 mins. at room temperature, before proteinase $K$ treatment was performed. Next, proteinase $\mathrm{K}$ was added every $24 \mathrm{~h}$ and digested for $72 \mathrm{~h}$ at $56{ }^{\circ} \mathrm{C}$ in a thermomixer. The extracted DNA was quantified using UV spectroscopy at $260 \mathrm{~nm}$.

\section{RNA extraction}

Between five and eight $5-\mu \mathrm{m}$ sections were cut from each block of FFPE tissue, and then the samples were deparaffinised with xylene and proteinase $K$ treated for $14 \mathrm{~h}$. Purification and DNase treatment - were performed using a Roche High Pure RNA Purification Kit (Roche Applied Sciences) and total RNA was stored at $-80{ }^{\circ} \mathrm{C}$ after extraction.

\section{DNA and RNA quality control}

The amount of DNA extracted was quantified using the NanoDrop and PicoGreen assay. RNA was quantified using the NanoDrop system, and the extent of degradation was measured using RT-qPCR for RPL13A mRNA with the primers defined by Illumina [7].

\section{cDNA-mediated annealing, selection and ligation (DASL) assay and gene expression profiling}

During the DASL assay, total RNA was converted to cDNA in a reverse transcription reaction using biotinylated oligo-(dT) 18 and random hexamers. Pairs of query oligonucleotides, with three unique pairs for each of 502 genes, were annealed to complementary sequences $(\sim 50$ base pairs) flanking the specific cDNA target site. The biotinylated cDNA was then bound to streptavidin beads, and mis-hybridised and non-hybridised oligonucleotides were washed away. Through a primer extension and ligation process, the biotinylated product was generated, and this was then amplified by universal fluorescent primers using conditions described below to fluorescently label and amplify the template cDNA. The $5^{\prime}$ primers were labelled with $\mathrm{Cy} 3$ and $\mathrm{Cy} 5$ fluorogenic dyes, respectively, while the 3 ' primer contained the address sequence that is complementary to a secondary address sequence located on array (SAM). The amplified cDNA was then denatured and hybridised to the SAM at $60{ }^{\circ} \mathrm{C}$ in a hybridisation oven with an oscillating table. Following overnight hybridisation, the array was washed and then scanned using the BeadArray reader (Illu$\operatorname{mina}^{\mathrm{Tu}}{ }^{\mathrm{x}}$. Image processing and intensity data files were analysed using BeadStudio software.

The probes used for the DASL assay were sourced from a cancer panel which consisted of 502 genes generated using 10 publically available data sets (http:// www.gtbiotech.com.tw/pdf/DASL\%20Assay\%20-

Work\%20Flow.pdf). The selection was based on their frequency of citation in the lists and also their association with cancer.

\section{Allelic composition analysis: molecular inversion probe (MIP) assay}

DNA $(2.35 \mu \mathrm{l})$ was mixed with $1.1 \mu \mathrm{l}$ of $53 \mathrm{~K}$ probe pool (200 amol/ $\mu \mathrm{l} /$ probe) and placed in a 96 -well plate in ice. The reaction mixture was incubated at $20^{\circ} \mathrm{C}$ for 4 mins, and $95{ }^{\circ} \mathrm{C}$ for 5 mins, then $58{ }^{\circ} \mathrm{C}$ overnight. Next, $13 \mathrm{ml}$ of a second enzyme mix and buffer were added. The MIPs were circularised by the addition of $4 \mu$ of dinucleotides (dATP with dTTP, dCTP and dGTP) and mixed at $58{ }^{\circ} \mathrm{C}$ for 10 mins. The non-circularised probes and genomic DNA were eliminated by the addition of $4 \mu \mathrm{l}$ of exonuclease mix and incubated at $37{ }^{\circ} \mathrm{C}$ for 15 mins, and then heat treated. The circularised probes were linearised by adding cleavage enzyme mix at $37^{\circ} \mathrm{C}$ 
for 15 mins, then subjected to universal primer amplification for 18 cycles at $95{ }^{\circ} \mathrm{C}$ for $20 \mathrm{~s}, 64{ }^{\circ} \mathrm{C}$ for $40 \mathrm{~s}$, and $72{ }^{\circ} \mathrm{C}$ for $10 \mathrm{~s}$. For the labelling reaction, products were further amplified with labelled primers for 10 ten cycles, and then subjected to cleavage by a digestion enzyme mix at $37{ }^{\circ} \mathrm{C}$ for $2 \mathrm{~h}$. The products were mixed with a hybridisation cocktail, denatured and hybridised to Affymetrix Universal $70 \mathrm{~K}$ Tag arrays at $39{ }^{\circ} \mathrm{C}$ for $16 \mathrm{~h}$ (two arrays per sample). After overnight hybridisation, arrays were washed on Affymetrix GeneChip Fluidics Station 450 and stained by streptavidin-phycoerythrin (SAPE) at $5 \mathrm{mg} / \mathrm{ml}$ (Invitrogen).

\section{Data analysis}

The data from the MIP arrays were normalized using a 2 pSE structuring element, which has been established as the best method for normalising MIP data [30]. Two different algorithms were used for copy number analysis. First, the data was then segmented using the circular binary segmentation (CBS) algorithm [31]. This algorithm splits the data into segments of equal copy number. A more refined analysis was done using the reverse jump array comparative genomic hybridisation (RJaCGH) algorithm, that fits a non-homogeneous hidden Markov model using reversible jump Markov chain Monte Carlo computation, and that takes into account model uncertainty using Bayesian model averaging $[32,33]$. This method estimates the probability that a region/gene has a copy number alteration (rather than a $p$ value or smoothed mean) and is useful in both basic and clinical applications. This algorithm also takes into account the distance between the probes, and is for this platform where there is an uneven distribution of markers on each chromosome. For example, in densely covered areas, the copy number of one probe is indicative of the copy number throughout the whole area. In contrast, in poorly covered areas where the probes are further apart, it is possible that copy number alterations will have occurred, but not be detected, so each probe provides much less information about the state of the neighbouring probes. Therefore, the distance between the probes needs careful consideration to ensure that the data provided by the consecutive probes was recorded accurately. This algorithm has the ability to assess data for each chromosome or on a genome-wide basis.

Agglomerative hierarchical clustering was carried out using the base $\mathrm{R}$ package function hclust with Ward's method. This allows compact clusters to be generated from the data and uses an analysis of variance approach to determine the distance between the clusters [34]. The smaller the increase in the sum of the within-group sum of squares, when two clusters are merged, the closer the two clusters. The within-group sum of squares was defined as the sum of squares of the distance between all objects in the cluster and the mean centroid of the cluster.
Robustness of the cluster was assessed using the $R$ package pvclust method [35]. This method assesses the uncertainty in hierarchical clustering by calculating quantiles called a $p$-value via multi-scale bootstrap resampling. Gene ontology assessment was carried out for the data using the Bioconductor package GOstats [36].

Quality control checks were carried out on the extracted data to identify any spatial effects or problems with probes. For the initial analysis, the data were quantile normalised, and hierarchical clustering was undertaken to assess the robustness of the platform. Hierarchical clustering is a robust method used to assess the relationship between samples. To assess robustness, a more detailed analysis of the probes and replicate arrays was carried out with the aim of further removing any noise. The MA and XY plots for the red and green channels were used to assess the array quality between the replicates, and those that did not agree with the replicates were removed.

For gene expression profiling, the majority of samples were assessed with multiple replicates. Pearson's correlation coefficient $(r)$ was used to assess the reproducibility of the probes between replicates, and where $r^{2}<0.7$ these data were excluded. The genes involved were initially selected as they passed the stringent criteria described. The average red and green signals of these probes were calculated and the data were quantile normalised. A subsequent analysis of the data was then undertaken.

\section{Results}

\section{Patient characteristics}

Forty-three of the $63(68 \%)$ patients treated in the NAC had sufficient DNA following extraction for analysis, while RNA was extracted from 52 of 63 (82\%) FFPE core biopsies. For CNA, 43 samples were used, while 46 samples were used for gene expression analysis. Clinical information and the tumour characteristics of the patients in this cohort are shown in Table 1 (Additional file 1). The mean age of the patients was 50 years (range 32$70), 33(72 \%)$ of the tumours were T2, while $27(58 \%)$ were grade 3 . Of the patients, $30(65 \%)$ had ER positive and a pCR was found in $30 \%(14 / 46)$ of the patients following NAC.

\section{Correlation between IHC, gene expression and copy numbers}

The median DNA yield per sample was $325 \mathrm{ng}$ (range 198-2000) while the RNA yield was $1800 \mathrm{ng}$ (range 114-3696). The matched normal tissues from a cohort of samples were used for normalising copy number data. Six of the 43 tumours exhibited gains or amplification in HER-2 when assessed using the MIP assay (14\%). When correlated with assessment by immunohistochemistry (IHC), five samples had an IHC score of $3+(83 \%)$, a further three samples had an IHC score of $2+$. 
Table 1 Characteristics of the patients used for expression and copy number analysis

\begin{tabular}{ll}
\hline Mean Age (Years) & 50 \\
Range & $32-70$ \\
Tumour Type & \\
Ductal Carcinoma & $44(96 \%)$ \\
Lobular Carcinoma & $2(4 \%)$ \\
Tumour Grade & \\
1 & $3(7 \%)$ \\
2 & $16(35 \%)$ \\
3 & $27(58 \%)$ \\
Tumour Stage (Breast) & \\
T1 & $5(11 \%)$ \\
T2 & $33(72 \%)$ \\
T3 & $6(13 \%)$ \\
T4 & $2(4 \%)$ \\
Oestrogen Receptor & \\
Positive & $30(65 \%)$ \\
Negative & $16(35 \%)$ \\
Pathological Response & \\
Pathological Complete Response (pCR) & $14(30 \%)$ \\
No Pathological Complete Response (Non-pCR) & $32(70 \%)$ \\
\hline
\end{tabular}

Gene expression, as assessed by the DASL assay, was compared with IHC to assess the reliability of the platform. The IHC scores for ER, PR, HER-2 and BCL2 proteins were compared with DASL gene expression results. Gene expression was dichotomised using a median cutoff, and an area under the curve (AUC) was generated to compare the two platforms (Table 2).

Gene expression of ESR1 was assessed using the three probes of the DASL assay, compared with the IHC ERpositive and -negative status (Fig. 1). As shown, ERpositive tumours exhibited elevated ESR1 expression compared with ER-negative cancers, and the difference was statistically significant (linear regression $p$ value $=0.023$ ) . The AUC analysis comparing the two platforms exhibited robust overlap with values of $0.77-0.8(p=0.002)$.
However, the correlation between the two platforms was in the range of 0.4-0.8, depending on the probes used. The probe-specific variation in the signal is very clear as the ESR1_3 had a lower signal compared with the other two probes and, as shown, this also has a lower AUC. Detailed analysis of the primer binding sites on the ESR1 gene showed that the probe with a lower AUC binds to a site closer to the $5^{\prime}$-UTR (un-translated region) than the other two probes, with a high gene expression signal (Additional file 2).

A similar comparison was carried out for HER-2, where a significant difference in gene expression was found according to the HER-2 status assessed by IHC, with the cancers classed as IHC $3+$ having a greater expression value $(p=0.022$, Fig. 1$)$. The AUC was $0.91-$ 0.95 using this probe $(p<0.001)$ and the correlation was 0.75-0.81. When this analysis was used to assess $P G R$ and BCL2 status, there was again a difference in gene expression between those classed as positive and those classed as negative (linear regression $p=0.0002$ for $P G R$ and $p=0.01$ for $B C L 2)$. The AUC for these two genes was $>0.70(p<0.05)$ for all probes except for one of the $B C L 2$ probes, and the correlation was also significant for all probes except this $B C L 2$ probe (Table 2).

\section{Copy number changes in breast cancer}

The regions with the highest frequency of gains $(>30 \%)$ comprised 1q (42\%), 8q (40\%), 11q (40\%), 17q (32\%) and 20q (35\%) (Fig. 2). A high frequency of gains was also observed in smaller regions of $5 \mathrm{p} 15.31$ (45\%), 5q15.2 (51\%), 5q23.1 (53\%), 12q24.22 (49\%) and $14 \mathrm{q} 21.3(51 \%)$. The regions identified as having the highest frequency of loss comprised $4 \mathrm{p}$ (34\%), $4 \mathrm{q}$ (34\%), 6q (43\%), 8p (30\%), 13q (30\%), 16q (30\%) and 18q (35\%) (Fig. 2) (Additional file 3).

The copy number data were analysed using clustering methods to identify any robust groups in this cohort. Unsupervised clustering showed that there were two distinct groups - 1 and 2 - with distinct pathological features. In Group 1, 83\% of the cancers (15/18) were ERpositive tumours. Group 2 was more heterogeneous, with 10 ER-positive and 9 ER-negative tumours (Chi squared test, $p$ value $=0.001)$. The robustness of the

Table 2 The AUC for each DASL probe compared with $I H C$ and the correlation between gene expression assessed using DASL and IHC score ( ${ }^{*}$ statistically significant $\left.p<0.05,{ }^{* *} p<0.0001\right)$

\begin{tabular}{|c|c|c|c|c|c|c|}
\hline \multirow[t]{2}{*}{ Marker } & \multicolumn{3}{|c|}{ AUC for each probe } & \multicolumn{3}{|c|}{ Correlation for each probe } \\
\hline & 1 & 2 & 3 & 1 & 2 & 3 \\
\hline Oestrogen receptor & $0.95^{* *}$ & $0.83^{*}$ & $0.75^{*}$ & $0.77^{* *}$ & $0.57^{* *}$ & $0.44^{*}$ \\
\hline Epidermal growth factor receptor -2 & $0.96^{* *}$ & $0.96^{* *}$ & $0.94^{* *}$ & $0.75^{* *}$ & $0.75^{* *}$ & $0.81^{* *}$ \\
\hline Progesterone receptor & $0.72^{*}$ & $0.90^{*}$ & $0.90^{*}$ & $0.36^{*}$ & $0.66^{*}$ & $0.64^{*}$ \\
\hline BCL2 expression & $0.74^{*}$ & $0.8^{*}$ & 0.46 & $0.40^{*}$ & $0.60^{*}$ & 0.11 \\
\hline
\end{tabular}



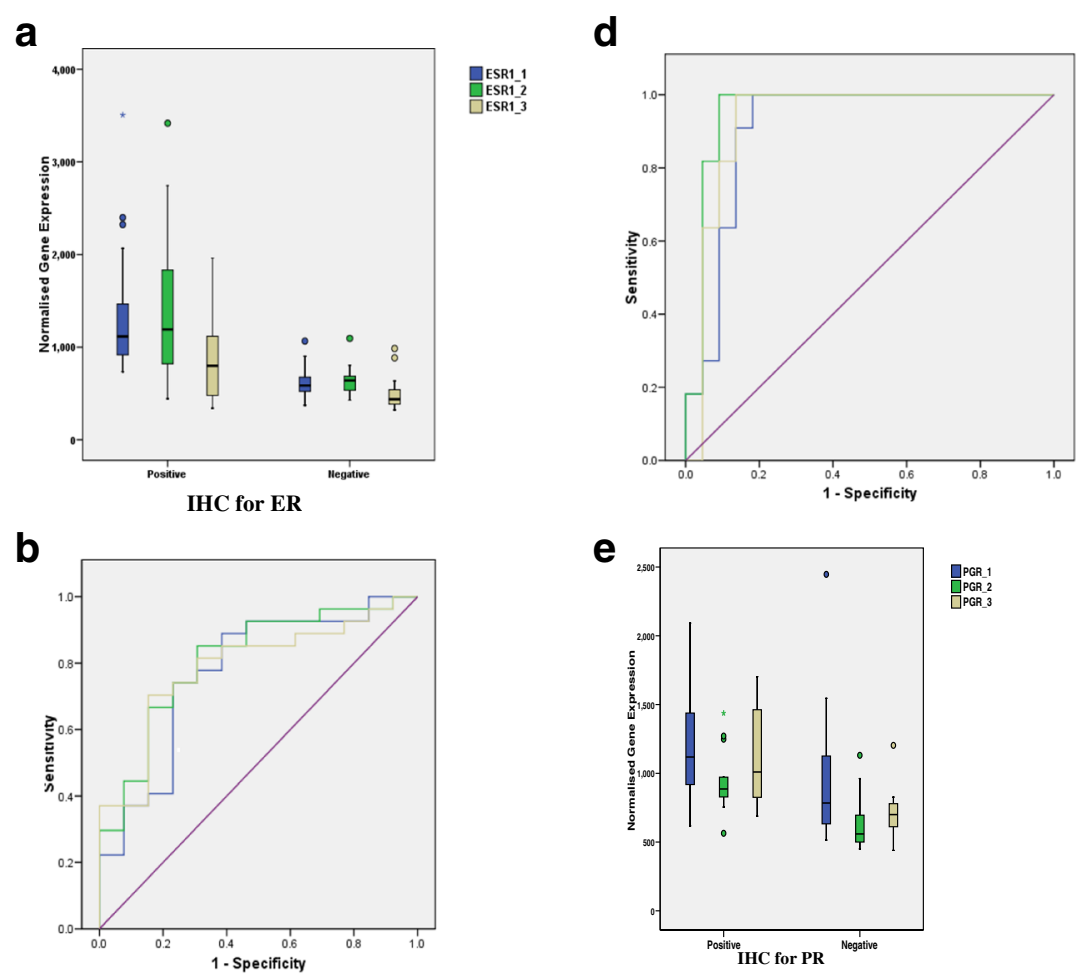

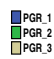
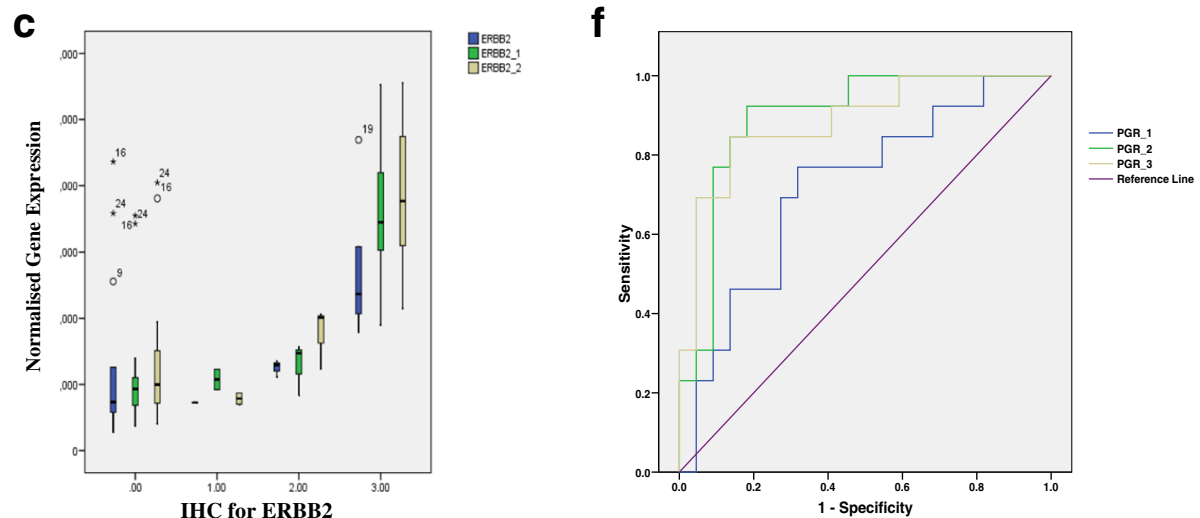

Fig. 1 Box plot showing gene expression in cancers according to IHC status and the Area Under the Curve (AUC) for each of the probes for each marker (number of samples). $\mathbf{a} \& \mathbf{b}=$ oestrogen receptor expression (positive $=30$ \& negative $=16$ ), (c \& $\mathbf{d}$ ) = ERBB-2 expression 0 (15), 1 (2),2 (5) \& 3 (6), (e \& $\mathbf{f}$ ) = progesterone receptor expression (positive- 20 \& negative 20) (Outlier samples shown by stars and numbers)

clusters was assessed using the pv-clust software package, which provides an approximate unbiased $p$ value and bootstrapping probability. This showed that the clusters are distinct with defined features.

The effect of copy number gains of known oncogenes such as ERBB2, CCND1 and C-MYC in breast cancer, was used to assess the robustness of the platform. Of the breast cancers assessed, there were gains in HER-2 in $33 \%$, CCND1 in $32 \%$, and $C-M Y C$ in $39 \%$. The survival analysis of the patients with these gains showed that $H E R-2$ amplification and $C-M Y C$ gain was associated with poor overall survival and that the frequency of these gene CNA are similar to that described in other breast cancer studies.

\section{Description of gains and losses and correlation with pathology}

The ER-positive tumours had the highest frequency of gains in 1q and 8q, while there were focal gains in 11q11 and 20q13. In ER-negative tumours, $11 \mathrm{p}$ and $17 \mathrm{q}$ had the highest frequency of gain.

When grade 3 and 1 tumours were compared, 8q23.3q24.11 (49\% vs $17 \%), 8 \mathrm{q} 24.11$ (48\% vs $16 \%)$ and $8 \mathrm{q} 24.21$ 


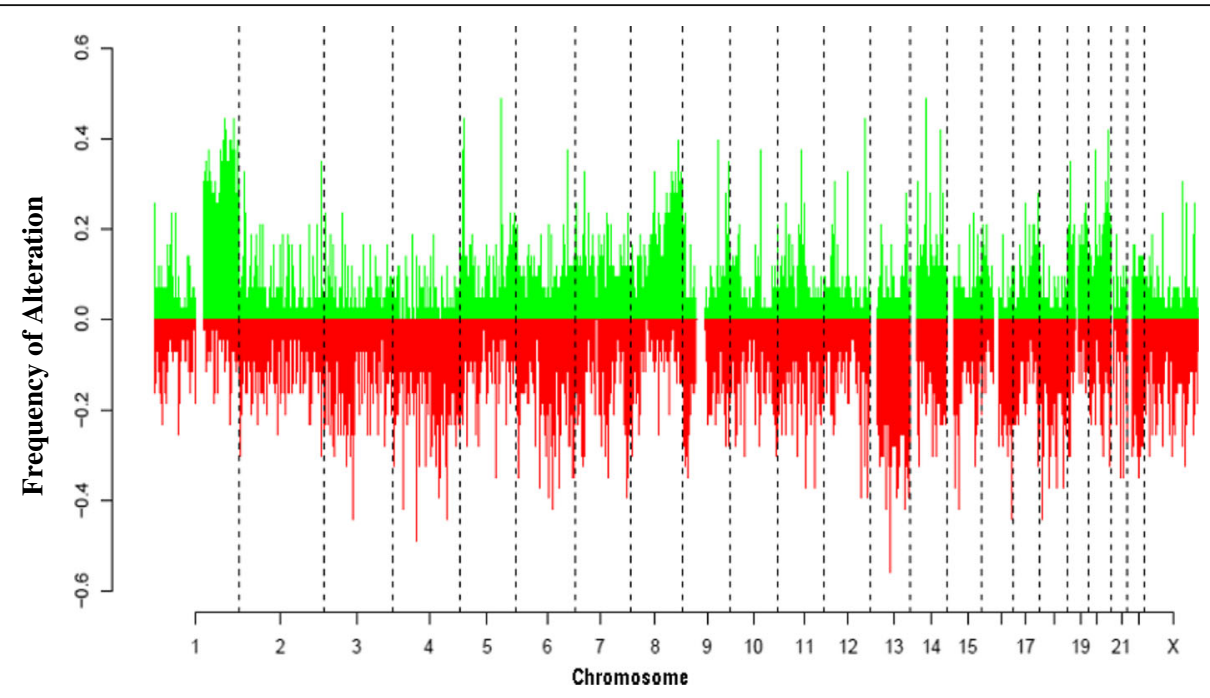

Fig. 2 Chromosomal plot showing copy number aberrations in all tumours analysed in the study (X-axis- chromosome number 1-X \& $Y$ axis frequency of alteration, Gains-green and Losses-red)

(43\% vs $9 \%$ ) were found to be more common in grade 3 lesions, while gains in $1 \mathrm{q} 21.1-\mathrm{q} 21.2$ (55\% vs 29\%), $1 \mathrm{q} 24.1$ (54\% vs 25\%), 1q21.2-21.3 (54\% vs $26 \%$ ), and 1 q22 (55\% vs $27 \%)$ were found to be more common in grade 1 tumours. These changes were statistically significant following multiple testing $(F D R<0.05)$. Loss at $16 q$ was seen in $40 \%$ of the grade 1 tumours compared with $18 \%$ of the grade 3 tumours.

When CNA and responses to NAC were assessed, gains were frequent in 1q (55\%), 8q (40\%) and 17q (40\%) among pCR tumours, while $11 \mathrm{q} 11$ gain was more frequent among the non-pCR tumours. The data also showed that $8 \mathrm{p}(40 \%)$ and $13 \mathrm{q}(70 \%)$ losses were more common among the pCR tumours, but none of these regions were statistically significant.
Common regions of alteration associated with poor overall survival comprised gains in 11q13 (62\%), 8q24.21 (54\%), $8 \mathrm{q} 24.22(54 \%)$ and $20 \mathrm{q} 13.13(47 \%)(p<0.1)$. The region most frequently gained in patients with a good overall survival was 1q. There were several regions of 1q and these were: 1q31, 3 (39\%), 1q32.2 (39\%), 1q41 (39\%) and 1q31 (39\%).

\section{Gene expression profiling of the pre-treatment core biopsies - differential expression analysis}

Differential gene expression analysis was carried out to assess overlap with published data, and which would act as a validation of the role of the assay. Differentially expressed genes between the 30 ER-positive and 16 ERnegative cancers were assessed and, as shown, all the three ESR1 probes were classified as highly expressed in

Table 3 Top 10 differentially expressed genes (each probe) between oestrogen receptor positive and negative cancers

\begin{tabular}{|c|c|c|c|}
\hline FDR & Log-Fold Change & Genes & Gene name \\
\hline $1.90 \mathrm{E}-07$ & 1.992 & TFF1 & $\begin{array}{l}\text { TREFOIL FACTOR } 1 \text { (BREAST CANCER, OESTROGEN-INDUCIBLE } \\
\text { SEQUENCE EXPRESSED IN) }\end{array}$ \\
\hline 7.13E-06 & 1.511 & ESR1 & OESTROGEN RECEPTOR 1 \\
\hline $6.90 \mathrm{E}-05$ & 1.568 & ESR1 & OESTROGEN RECEPTOR 1 \\
\hline $1.00 \mathrm{E}-03$ & 1.012 & LAF4 & NUCLEAR PROTEIN RELATED TO AF4 \\
\hline $1.00 \mathrm{E}-03$ & 1.299 & ESR1 & OESTROGEN RECEPTOR 1 \\
\hline $2.00 \mathrm{E}-03$ & 0.780 & C-MYB & V-MYB MYELOBLASTOSIS VIRAL ONCOGENE HOMOLOGUE (AVIAN) \\
\hline 3.00E-03 & 1.464 & AREG & AMPHIREGULIN (SCHWANNOMA-DERIVED GROWTH FACTOR) \\
\hline 3.00E-02 & -0.964 & CD44 & CD44 ANTIGEN (INDIAN BLOOD GROUP) \\
\hline 3.00E-02 & 0.765 & LAF4 & NUCLEAR PROTEIN RELATED TO AF4 \\
\hline $3.50 \mathrm{E}-02$ & 0.800 & ERBB4 & $\begin{array}{l}\text { V-ERB-A ERYTHROBLASTIC LEUKEMIA VIRAL ONCOGENE HOMOLOGUE } \\
4 \text { (AVIAN) }\end{array}$ \\
\hline
\end{tabular}


ER-positive cancers and were significant on multiple testing (FDR $p \leq 0.001$ ) (Table 3) (Additional files 4, 5, 6, 7).

This analysis also showed that other oestrogenregulated genes such as TFF1, PGR and $C-M Y B$ were also present in the top 25 genes classified as highly differentially expressed (FDR $p<0.05$ ). LAF4 and AREG showed high expression in ER-positive breast cancers, and all three transcripts showed high expression among ER-positive breast cancers. Due to small the sample size these changes could be biologically not significant and need further validation.

Grade 1 and 3 tumours were also assessed to identify those genes that were differentially expressed between the high-grade and low-grade tumours. As shown below, BIRC5, ERBB4, SOD1, ARHGDIB and CDC25B were the top 4 differentially expressed genes (Table 4 ). All the genes, apart from $E R B B 4$, were over-expressed in grade 3 tumours compared with grade 1 tumours, and all three $E R B B 4$ transcripts were present in the top 25 genes.

Although gene expression changes are statistically significant, some of the log fold changes are small and might not contribute to meaningful biological or physiological changes. This is especially the case when limited number of samples are used, hence both further validation and functional analysis is important for confirming the role of any potential markers in any study such as this.

The pCR rate following NAC study was 26\% (12/46) and the expression profiles of these samples were used to assess differentially expressed genes between patients whose tumours had a pCR or non-pCR with NAC. The top three differentially expressed genes were CXCL9, $A R H A$ and $A R H G D I B$, but this observation was not statistically significant on multiple testing ( $p<0.11$, Table 5 ). All three $A R H G D I B$ alternate transcripts exhibited elevated expression in patients with $\mathrm{pCR}$. There was lower expression of the multi-drug resistant transporter, $A B C G 2$ gene, in those tumours with a pCR following NAC.
Gene ontology assessment of the top 50 differentially over-expressed genes indicated that the two most significantly-enriched GO categories were regulators of biological processes $(61 \%$ of which were genes such as $M Y B$, $A R H D I B$ and CDK9) and cellular metabolic processes (61\% of which were genes such as MAPK14, SKIL and FGFR3).

\section{Gene expression and copy number changes}

The best performing 308 probes were correlated with copy number data. Overall, when all the reliable probe expression and copy number were compared, 25\% probes had a Pearson correlation $>0.26$ and $50 \%$ more than $>0.14$. For certain probes, such as those targeting $E R B B 2, C C N D 1, G R B 7$, and BIRC5, there was good concordance observed between gene expression and locus copy number (Table 6). Nevertheless, in some instances, there was diminished correlation between detected copy number and quantified mRNA expression, as seen with probes 1 and 2 for the FGF3 gene (FGF-P1 and FGF-P3). Results for the well-characterised tumour suppressor gene $C D H 1$ indicated a correlation of 0.4 , while TOP $2 A$ had a correlation of 0.44 . A strong correlation was also found between copy number and mRNA expression for other genes in regions such as 11q13 (CCD1), 20q13 $(B-M Y B)$ and $17 \mathrm{q} 12$ (ERBB2).

Genes associated with a pCR and their relationship between copy number and gene expression were evaluated, TNFAIP1 was revealed as a locus that demonstrated a very high correlation between copy number and expression $(r=0.99)$ (Table 7$)$. None of the genes associated with $\mathrm{pCR}$ were statistically significant. Of the other genes, two of the three HER-2 transcripts exhibited strong correlations between expression and copy number and were further associated with pCR. The genes associated with ER-negative status and with high copy number and gene expression ratios comprised ERBB2, GRB2, STAT3, CCND1, MUC1 and FGFR3.

Table 4 Table showing the top 10 differentially expressed genes (each probe) between grade 1 and grade 3 tumours

\begin{tabular}{|c|c|c|c|}
\hline FDR & Log-Fold Change & Genes & Gene name \\
\hline 0.186 & 0.271 & BIRC5 & BACULOVIRAL IAP REPEAT-CONTAINING 5 (SURVIVIN) \\
\hline 0.186 & -0.337 & ERBB4 & $\begin{array}{l}\text { V-ERB-A ERYTHROBLASTIC LEUKAEMIA VIRAL ONCOGENE HOMOLOGUE } \\
4 \text { (AVIAN) }\end{array}$ \\
\hline 0.216 & 1.149 & SOD1 & $\begin{array}{l}\text { SUPEROXIDE DISMUTASE 1, SOLUBLE (AMYOTROPHIC LATERAL SCLEROSIS } \\
1 \text { (ADULT)) }\end{array}$ \\
\hline 0.247 & 0.723 & ARHGDIB & RHO GDP DISSOCIATION INHIBITOR (GDI) BETA \\
\hline 0.247 & 0.622 & CDC25B & CELL DIVISION CYCLE 25B \\
\hline 0.247 & 0.417 & CXCL9 & CHEMOKINE (C-X-C MOTIF) LIGAND 9 \\
\hline 0.247 & 0.964 & GRB7 & GROWTH FACTOR RECEPTOR-BOUND PROTEIN 7 \\
\hline 0.247 & 1.156 & HIF1A & $\begin{array}{l}\text { HYPOXIA-INDUCIBLE FACTOR 1, ALPHA SUBUNIT (BASIC HELIX-LOOP-HELIX } \\
\text { TRANSCRIPTION FACTOR) }\end{array}$ \\
\hline 0.247 & 1.117 & B-MYB & V-MYB MYELOBLASTOSIS VIRAL ONCOGENE HOMOLOGUE (AVIAN)-LIKE 2 \\
\hline 0.247 & -0.348 & PGR & PROGESTERONE RECEPTOR \\
\hline
\end{tabular}


Table 5 Table showing differentially expressed genes (each probe) between pathological complete responders (pCR) and those with no pathological complete response (non-pCR)

\begin{tabular}{llll}
\hline FDR & Log-Fold Change & Genes & Gene name \\
\hline 0.087 & 0.911 & CXCL9 & CHEMOKINE (C-X-C MOTIF) LIGAND 9 \\
0.104 & ARHA & RAS HOMOLOGUE GENE FAMILY, MEMBER A \\
0.104 & ARHGDIB & RHO GDP DISSOCIATION INHIBITOR (GDI) BETA \\
0.104 & BCL3 & B-CELL CLL/LYMPHOMA 3 \\
0.104 & 0.925 & CD44 & CD44 ANTIGEN (INDIAN BLOOD GROUP) \\
0.104 & 0.665 & CDKN1B & CYCLIN-DEPENDENT KINASE INHIBITOR 1B (P27, KIP1) \\
0.104 & 0.912 & CSF1R & COLONY STIMULATING FACTOR 1 RECEPTOR, FORMERLY \\
& 0.638 & & MCDONOUGH FELINE SARCOMA VIRAL (V-FMS) ONCOGENE \\
0.104 & & HOMOLOGUE \\
0.104 & 0.742 & DCN & EARLY GROWTH RESPONSE 1 \\
0.104 & 0.783 & EGR1 & LYMPHOCYTE-SPECIFIC PROTEIN TYROSINE KINASE \\
\hline
\end{tabular}

\section{Discussion}

This study has revealed that FFPE core biopsies can be used for integrative analysis of gene expression and copy number in breast cancer. The majority of core biopsies from patients could be used for gene expression analysis. Our findings have significant implications for the wider application of FFPE tissue in translational research and clinical use [2, 37, 38].

It is important to compare results from these new platforms with other established methods for molecular marker analysis, such as IHC. When gene expression was compared with IHC for routine markers, concordance was significant (ER; $p=0.002, H E R-2 ; p<0.001$,

Table 6 Correlation between gene expression and copy number for the robust probes used in the DASL assay (P1-3-identity of the probes used to assess each gene in the DASL assay) (Correlation between copy number and gene expression: $25 \%$ of probes $>0.26$ and $50 \%$ probes $>0.14$ )

\begin{tabular}{lll}
\hline $\begin{array}{l}\text { Gene name and } \\
\text { DASL probe number }\end{array}$ & $\begin{array}{l}\text { Correlation between } \\
\text { expression and copy number }\end{array}$ & $\begin{array}{l}95 \% \text { Confidence } \\
\text { Interval }\end{array}$ \\
\hline ESR1-P2 & 0.483 & {$[0.161-0.712]$} \\
JUND-P1 & 0.490 & {$[0.06-0.766]$} \\
MUC1-P2 & 0.497 & {$[0.144-0.738]$} \\
BIRC5-P1 & 0.500 & {$[0.17-0.729]$} \\
RAN-P1 & 0.503 & {$[0.152-0.741]$} \\
RELA-P1 & 0.525 & {$[0.172-0.758]$} \\
BIRC5-P2 & 0.527 & {$[0.205-0.745]$} \\
COMT-P1 & 0.556 & {$[-0.026-0.857]$} \\
FGFR1-P1 & 0.575 & {$[0.283-0.769]$} \\
GRB7-P1 & 0.585 & {$[0.192-0.816]$} \\
ERBB2-P1 & 0.733 & {$[0.43-0.888]$} \\
CCND1-P1 & 0.773 & {$[0.512-0.903]$} \\
HER-2-P2 & 0.800 & {$[0.553-0.918]$} \\
\hline
\end{tabular}

and $P R ; p=0.0002)$. Very few studies have attempted to compare gene expression profiling with IHC. Gong et al. used gene expression profiles of FF tissue to determine ESR1 and HER-2 status among a cohort of 495 breast cancer patients. The data from 195 tumours were used to define the cut-off, and the accuracy of the cut-off was assessed in 300 samples from two further series. This revealed that Spearman's correlation coefficient ranged from 0.62 to 0.77 . The correlation coefficients for ESR-1 and HER-2 were 0.77 and 0.81 , respectively, for the bestperforming probes using the DASL assay in these samples. This is very encouraging, and by using these probes, ER and HER-2 status can be reliably determined.

Abramovitz et al. also showed that there was high concordance between ER, PR and HER-2 IHC and DASL $(p<0.01)$, with significant differences between positive and negative tumours [39]. This degree of agreement is very similar to the extent of concordance observed when $E R$ and HER-2 FISH (fluorescence in situ hybridisation) assessments are carried out on the same samples in different laboratories [40]. These data are of interest as they suggest that DASL is a useful tool for molecular marker analysis.

We identified a high correlation between IHC for ERBB2 and MIP amplification of FFPE breast cancer specimen's 17q13 loci, with 83\% concordance between the two platforms. The concordance was $73 \%$ in Andre et al.'s

Table 7 Genes where there is a high correlation between copy number, expression and clinical feature

\begin{tabular}{ll}
\hline Clinical characteristic & $\begin{array}{l}\text { Genes where copy number and } \\
\text { expression correlation }>0.75\end{array}$ \\
\hline Pathological complete response & $\begin{array}{l}\text { TNFAIP1, JUND, HER-2, NFKBIA, PDGF, } \\
\text { IL13, CCND1 }\end{array}$ \\
Genes associated with ER- & GRB2, HER-2, STAT3, CCND1, MUC1, \\
negative status & FGFR3 \\
\hline
\end{tabular}


group of 68 patients and 100\% in the 61 patients in Pierga et al.'s series. Both these studies used FF DNA, which further confirms the robustness of the MIP assays [41, 42].

Nucleic acid base modifications and cross-linking occur following formalin fixation, rendering intact nucleic acid extraction difficult from these tissues [43]. Many groups have extracted DNA from FFPE tissue blocks and have shown that considerably less DNA can be extracted from FFPE tissues than from FF samples, and this limits its application [44]. Jacobs et al. and Oosting et al. used FFPE DNA from tumour for CNA employing the Affymetrix $500 \mathrm{~K}$ array and llumina SNP BeadChip. These platforms require $0.25-1 \mu \mathrm{g}$ of DNA to generate genome-wide copy number data $[45,46]$. The results from these investigations showed that the majority of core biopsy samples contain sufficient DNA for analysis using the Affymetrix $500 \mathrm{~K}$ array, but that only $60 \%$ of the samples in these studies could be analysed using the Illumina platform. These analyses used FFPE tissue blocks from which to extract DNA, but there is a considerable amount of material available from the initial diagnostic core biopsies in a majority of cases.

The MIP assay is well suited to the analysis of FFPE DNA as it only requires an intact 40-bp sequence and $<40 \mathrm{ng}$ of DNA as template [24]. Limitations of other platforms include a requirement for high DNA quantity and quality, and a high output of DNA following amplification, which cannot be achieved using PCR of FFPE samples, Furthermore, many samples exhibit PCR amplification bias due to short template fragment size [47].

Recurrent gains in chromosomes 1q, 8q, 11q, 17q and $20 \mathrm{q}$ and losses in $6 \mathrm{q}, 8 \mathrm{p}, 13 \mathrm{q}$ and $16 \mathrm{q}$ were frequently observed in this study. These identified copy number aberrations were similar to those described in previous studies where genome-wide changes were analysed by chromosomal CGH [48] and aCGH [23, 41, 49-51]. The majority of copy number studies to date have been carried out using FF samples and have employed platforms requiring high DNA input. Most studies have identified $8 \mathrm{q}, 11 \mathrm{q}, 17 \mathrm{q}$ and $20 \mathrm{q}$ as the most frequently gained regions. Andre et al. described gains in $8 \mathrm{q}(58 \%)$ and $1 \mathrm{q}$ (55\%) and losses in 8p (51\%) and 13q (41\%) as some of the commonest copy number changes using FF DNA, which concurs with our data, whereas gains in 11q, 17q and $20 \mathrm{q}$ were not frequent in their data set [41]. The study by Nessling et al. is one of the published studies where locus copy number changes in breast cancer using FFPE tissue were examined. Our data presented here overlap well with their findings. The authors of that study used a matrix-CGH platform containing 422 autosomal markers to profile 31 tumours, and it is encouraging that comparable changes can be identified in FFPE tissue using different platforms, as this suggests that the
DNA from such samples is a reliable, readily obtained source for DNA analysis.

Gains in 1q and 8q and losses in 16q were observed in ER-positive cancers, as described by others, while ER-negative tumours were more likely to over-express $17 q$ loci consistent with the observations of other groups [52].

This study was a feasibility study investigating the role of the integrative analysis of core biopsies for copy number and gene expression profiling and did not aim to discover new molecular markers. Even so, there were several regions in 1q, 8q and 20q that showed alterations in breast cancer with a pCR compared with those without pCR; these differences were not statistically significant. Using 106 fresh tumours, Andre et al. showed that regions in 3q, $6 p, 11 p, 11 q, 18 q$ and $19 q$ were significantly altered in breast cancers showing $\mathrm{pCR}$, compared with non-responders, but this did not reach statistical significance when adjusted for multiple testing (FDR $=0.59)$ [41].

This study used core biopsy tissue for RNA and DNA extraction and this data confirms that this is a resource that is suitable for molecular marker studies. In a large population-based study, tissue cores from melanoma biopsies were used for profiling using the DASL assay; only $1.4 \%$ of the samples failed to yield sufficient RNA using this approach. This is dependent on the age of the sample as older tissue blocks have lower yields and higher level of degradation [53].

Differential expression analysis was aimed at validating the platform further and identifying potential new molecular markers. Differential expression analysis between ER-positive and -negative tumours revealed that all three alternatively-spliced mRNA transcripts of ESR1 are (with TFF1) represented in the top four differentiallyexpressed genes. This is highly significant as we would expect the main discriminator to be ESR1 between these cohorts. TFF1 is also a well-characterised oestrogenregulated gene and has been shown to be upregulated in ER-positive breast cancers in multiple data sets $[54,55]$.

A proportion of gene expressions can be accounted for by underlying copy number alterations. Thus, identification of oncogenes that are amplified or lost may lead to the discovery of potential new molecular markers [56]. CNA will help to reveal which amplicons or regions are frequently altered in cancers. Subsequently, genes at these loci can be studied in more detail to characterise potential oncogenes or tumour suppressor genes. In addition, a high correlation was observed between copy number and gene expression in regions commonly amplified in breast cancer, such as 20q13 (B-MYB), 17q (HER-2) and 11q (CCND1).

There was a good correlation between copy number and expression among the pCRs for several genes including HER-2, CCND1, TNFAIP1 and JUND. This is a well-established relationship as many studies have shown that $H E R-2$ positivity is associated with higher response 
rates to NAC [57]. Penault-Llorca et al. observed that CCND1 positivity with IHC was increased following neoadjuvant chemotherapy, but they were unable to show a correlation with response to chemotherapy [58]. CCND1 is a frequently amplified gene in breast cancer and has been previously shown to be associated with improved disease-free and overall survival.

The genes assessed as part of the DASL cancer panel assay consisted of 502 genes derived from various published data sets where gene selection is biased towards haematological malignancies. This is not an ideal setting for 'class discovery' in breast cancer but represents a useful platform for an initial pilot study [59]. The unbiased, DASL WG assay - where all transcripts are assessed - is a superior platform, but was not available at the start of this study. This is a 'bottom-up' model for molecular marker studies as it only assesses a limited number of markers, although this approach has been successfully used in other studies [60]. For example, a similar approach was adopted by Paik et al. for deriving their Recurrence $\mathrm{Score}^{\mathrm{rm}}$, where they used an initial list of 250 genes from published studies; this was then used to arrive at their final selection of 16 genes [38]. A recent consensus statement on FFPE analysis suggested initially using a targeted pilot project to assess the robustness of the platform.

In our study, only a relatively small number of samples were investigated, and therefore it has a constraining power in detecting genes of significant effect, as shown in many other studies of similar size [61-63]. Nevertheless, ours was one of the first analyses of an FFPE platform to be carried out for breast cancer, to assess the platform and robustness compared with an IHC approach, using either DASL or any other technology for gene expression profiling employing FFPE tissue.

The results obtained using the DASL assay are comparable with those for IHC and the DASL assay has the potential to assess large numbers of markers, hence enabling large numbers of samples to be evaluated for potential molecular markers. This is particularly valuable in cancers where there is limited availability of fresh tissue. In our study, core biopsy samples were successfully used for CNA using an MIP assay. This shows that both the DASL and the MIP assays provide a valuable tool for molecular marker studies in cancer.

\section{Conclusion}

Integrated genomic and transcriptomic analysis of FFPE samples will allow rapid progress in molecular marker identification in cancer research. This is one of the first studies, to have shown the use of FFPE samples to assess gene expression and copy number analysis. The expression profiles from FFPE samples correlated with those from FF samples. Therefore, FFPE samples can be more readily used for translational research in the future.

\section{Additional files}

Additional file 1: Clinical Data - The Sample ID and the Nature of samples (C-cancer or N-Normal), Tumor grade (1, 2, or 3, N/A) and oestrogen Receptor Status (1-positive, 2-negative or N/A- not available). (TXT 1 kb)

Additional file 2: Oestrogen Receptor data. The Oestrogen receptor SNP's and their effect on probe expression (ESR- SNPs). Box plot of the expression in each of the three probes of ESR1 against each SNP (no significant difference on ANOVA). (PDF $16 \mathrm{~kb}$ )

Additional file 3: Molecular Inversion Probe Copy Number data. The data including probe signal, probe position, call rate, copy number relative standard deviation, Copy Number and Allelic ratio. (TXT 84778 kb)

Additional file 4: DASL Assay sample sheet (Assay ID 4139683017). The sample sheet containing the sample ID, replicates, array position. (CSV $5 \mathrm{~kb}$ )

Additional file 5: DASL Assay sample sheet (Assay ID 4139683008). The sheet sample containing the sample ID, replicates, array position. (CSV $4 \mathrm{~kb}$ )

Additional file 6: DASL Data from Assay ID 4139683017. (ZIP $4853 \mathrm{~kb}$ )

Additional file 7: DASL Data from Assay ID 4139683008. (ZIP $2739 \mathrm{~kb}$ )

\section{Abbreviations}

AUC: Area Under the Curve; CNA: Copy Number Analysis; CGH: Comparative Genomic Hybridisation; DASL: cDNA-Mediated, Annealing, Selection, Extension and Ligation Assay; DNA: Deoxyribonucleic acid; ER: Oestrogen Receptor Protein; ESR: Oestrogen Receptor Gene; FFPE: Formalin Fixed Paraffin Embedded; HER-2: Human Epidermal Growth Factor Receptor Type 2 Protein; IHC: Immunohistochemistry; MIP: Molecular Inversion Probes; NAC: Neoadjuvant Chemotherapy; PCR: Polymerase Chain Reaction; PGR: Progesterone Receptor Gene; PR: Progesterone Receptor Protein; RNA: Ribonucleic Acid; SNP: Single Nucleotide Polymorphism

\section{Acknowledgements}

Nil.

\section{Funding}

This work and Ml was funded by Addenbrooke's Charitable Trust and Cancer Research UK. The funding bodies did not play any role in the design of the study and collection, analysis, and interpretation of the data and in writing the manuscript.

\section{Availability of data and materials}

All the copy number data, DASL gene expression data and samples sheets have been deposited to a public repository and available to download (https://figshare.com/articles/Iddawela_et_at_Integrative_analysis_of_copy_ number_and_gene_expression_using_formalin-fixed_paraffinembeded_ core_biopsy_tissue_a_feasibility_study/4312046).

\section{Authors' contributions}

$\mathrm{Ml}$ designed and performed the experiments. OR and MI performed data analysis. OE, JE and JC contributed samples and data. MI, OR, HME, JE, OE and CC wrote the manuscript, with input from all authors. HME and CC

supervised the research. All authors read and approved the final manuscript.

\section{Competing interests}

The other authors declare that they have no competing interests.

Consent for publication Not applicable.

\section{Ethics approval and consent to participate}

This study was approved by the Cambridge University Hospitals Research Ethics Committee and the United Lincolnshire Hospital's Research Ethics Committee. The patients provided written consent to the study and for the analysis of the samples.

\section{Publisher's Note}

Springer Nature remains neutral with regard to jurisdictional claims in published maps and institutional affiliations. 


\section{Author details}

Cancer Research UK Cambridge Institute, Li Ka Shing Centre, Robinson Way, Cambridge CB2 ORE, UK. ${ }^{2}$ Department of Oncology, University of Cambridge, Addenbrooke's Hospital, Hills Road, Cambridge, UK. ${ }^{3}$ Cambridge Breast Unit, Addenbrooke's Hospital, Cambridge University Hospitals NHS Foundation Trust, NIHR Cambridge Biomedical Research Centre and Cambridge Experimental Cancer Medicine Centre, Cambridge, UK. ${ }^{4}$ Department of Anatomy \& Developmental Biology, Monash University, Clayton, VIC 3800, Australia. ${ }^{5}$ School of Clinical Sciences, Monash University, Clayton, Australia. ${ }^{6}$ Research and Development, Lincoln Breast Unit, Lincoln County Hospital, Lincoln, UK. ${ }^{7}$ Nottingham Digestive Disease Centre, Faculty of Medicine and Health Sciences, University of Nottingham, Queen's Medical Centre, Nottingham, UK. ${ }^{8}$ PathLinks, Lincoln County Hospital, Lincoln, UK.

\section{Received: 16 December 2016 Accepted: 16 June 2017} Published online: 11 July 2017

\section{References}

1. Duffy MJ. Predictive markers in breast and other cancers: a review. Clin Chem. 2005:51(3):494-503.

2. Paik S. Development and clinical utility of a 21-gene recurrence score prognostic assay in patients with early breast cancer treated with tamoxifen. Oncologist. 2007;12(6):631-5.

3. Buus R, Sestak I, Kronenwett R, Denkert C, Dubsky P, Krappmann K, Scheer M, Petry C, Cuzick J, Dowsett M. Comparison of EndoPredict and EPClin With Oncotype DX Recurrence Score for Prediction of Risk of Distant Recurrence After Endocrine Therapy. J Natl Cancer Inst. 2016;108(11):1-7.

4. Nielsen TO, Parker JS, Leung S, Voduc D, Ebbert M, Vickery T, et al. A comparison of PAM50 intrinsic subtyping with immunohistochemistry and clinical prognostic factors in tamoxifen-treated estrogen receptor-positive breast cancer. Clin Cancer Res. 2010;16(21):5222-32.

5. Curtis C, Shah SP, Chin SF, Turashvili G, Rueda OM, Dunning MJ, et al. The genomic and transcriptomic architecture of 2,000 breast tumours reveals novel subgroups. Nature. 2012;486(7403):346-52.

6. Sorlie T, Perou CM, Tibshirani R, Aas T, Geisler S, Johnsen H, et al. Gene expression patterns of breast carcinomas distinguish tumor subclasses with clinical implications. Proc Natl Acad Sci U S A. 2001;98(19):10869-74.

7. Bibikova M, Yeakley JM, Wang-Rodriguez J, Fan JB. Quantitative expression profiling of RNA from formalin-fixed, paraffin-embedded tissues using randomly assembled bead arrays. Methods Mol Biol. 2008;439:159-77.

8. von Ahlfen S, Missel A, Bendrat K, Schlumpberger M. Determinants of RNA quality from FFPE samples. PLoS One. 2007;2(12):e1261.

9. Barnes M, Freudenberg J, Thompson S, Aronow B, Pavlidis P. Experimental comparison and cross-validation of the Affymetrix and Illumina gene expression analysis platforms. Nucleic Acids Res. 2005;33(18):5914-23.

10. Fan JB, Yeakley JM, Bibikova M, Chudin E, Wickham E, Chen J, et al. A versatile assay for high-throughput gene expression profiling on universal array matrices. Genome Res. 2004;14(5):878-85.

11. Bibikova M, Talantov D, Chudin E, Yeakley JM, Chen J, Doucet D, et al. Quantitative gene expression profiling in formalin-fixed, paraffin-embedded tissues using universal bead arrays. Am J Pathol. 2004;165(5):1799-807.

12. Iddawela M, Rueda OM, Klarqvist M, Graf S, Earl HM, Caldas C. Reliable gene expression profiling of formalin-fixed paraffin-embedded breast cancer tissue (FFPE) using CDNA-mediated annealing, extension, selection, and ligation whole-genome (DASL WG) assay. BMC Med Genet. 2016;9(1):54.

13. Bibikova M, Chudin E, Arsanjani A, Zhou L, Garcia EW, Modder J, et al. Expression signatures that correlated with Gleason score and relapse in prostate cancer. Genomics. 2007;89(6):666-72.

14. Conway C, Mitra A, Jewell R, Randerson-Moor J, Lobo S, Nsengimana J, et al. Gene expression profiling of paraffin-embedded primary melanoma using the DASL assay identifies increased osteopontin expression as predictive of reduced relapse-free survival. Clin Cancer Res. 2009;15(22):6939-46.

15. Hammoud ZT, Badve S, Zhao Q, Li L, Saxena R, Thorat MA, et al. Differential gene expression profiling of esophageal adenocarcinoma. J Thorac Cardiovasc Surg. 2009;137(4):829-34.

16. Slamon DJ, Clark GM, Wong SG, Levin WJ, Ullrich A, McGuire WL. Human breast cancer: correlation of relapse and survival with amplification of the HER-2/neu oncogene. Science. 1987;235(4785):177-82.

17. Bagatell R, Beck-Popovic M, London WB, Zhang Y, Pearson AD, Matthay KK, et al. Significance of MYCN amplification in international neuroblastoma staging system stage 1 and 2 neuroblastoma: a report from the international Neuroblastoma risk group database. J Clin Oncol. 2009;27(3):365-70.

18. Hashimoto H, Daimaru Y, Enjoji M, Nakagawara A. N-myc gene product expression in neuroblastoma. J Clin Pathol. 1989:42(1):52-5.

19. Boshoff C, Posner M. Targeting EGFR in head and neck cancer: a decade of progress. Nat Clin Pract Oncol. 2009;6(3):123.

20. Grandis JR, Tweardy DJ. Elevated levels of transforming growth factor alpha and epidermal growth factor receptor messenger RNA are early markers of carcinogenesis in head and neck cancer. Cancer Res. 1993;53(15):3579-84.

21. Grandis JR, Tweardy DJ. TGF-alpha and EGFR in head and neck cancer. J Cell Biochem Suppl. 1993;17F:188-91.

22. Nessling M, Richter K, Schwaenen C, Roerig P, Wrobel G, Wessendorf S, et al. Candidate genes in breast cancer revealed by microarray-based comparative genomic hybridization of archived tissue. Cancer Res. 2005;65(2):439-47.

23. Callagy G, Pharoah P, Chin SF, Sangan T, Daigo Y, Jackson L, et al. Identification and validation of prognostic markers in breast cancer with the complementary use of array-CGH and tissue microarrays. J Pathol. 2005; 205(3):388-96

24. Wang Y, Carlton VE, Karlin-Neumann G, Sapolsky R, Zhang L, Moorhead M, et al. High quality copy number and genotype data from FFPE samples using molecular inversion probe (MIP) microarrays. BMC Med Genet. 2009;2:8.

25. Wang Y, Moorhead M, Karlin-Neumann G, Wang NJ, Ireland J, Lin S, et al. Analysis of molecular inversion probe performance for allele copy number determination. Genome Biol. 2007;8(11):R246.

26. Jahromi MS, Putnam AR, Druzgal C, Wright J, Spraker-Perlman H, Kinsey M, et al. Molecular inversion probe analysis detects novel copy number alterations in Ewing sarcoma. Cancer Genet. 2012;205(7-8):391-404.

27. Schiffman JD, Wang Y, McPherson LA, Welch K, Zhang N, Davis R, et al. Molecular inversion probes reveal patterns of 9p21 deletion and copy number aberrations in childhood leukemia. Cancer Genet Cytogenet. 2009;193(1):9-18.

28. Chin SF, Teschendorff AE, Marioni JC, Wang Y, Barbosa-Morais NL, Thorne NP, et al. High-resolution aCGH and expression profiling identifies a novel genomic subtype of ER negative breast cancer. Genome Biol. 2007;8(10):R215.

29. Paik S, Kim CY, Song YK, Kim WS. Technology insight: application of molecular techniques to formalin-fixed paraffin-embedded tissues from breast cancer. Nat Clin Pract Oncol. 2005;2(5):246-54.

30. Wang Y, Moorhead M, Karlin-Neumann G, Falkowski M, Chen C, Siddiqui F, et al. Allele quantification using molecular inversion probes (MIP). Nucleic Acids Res. 2005;33(21):e183.

31. Olshen $A B$, Venkatraman ES, Lucito R, Wigler M. Circular binary segmentation for the analysis of array-based DNA copy number data. Biostatistics. 2004;5(4):557-72.

32. Rueda OM, Diaz-Uriarte R. Flexible and accurate detection of genomic copynumber changes from aCGH. PLoS Comput Biol. 2007;3(6):e122.

33. Rueda OM, Diaz-Uriarte R: RJaCGH: Bayesian analysis of aCGH arrays for detecting copy number changes and recurrent regions. Bioinformatics. 2009:25(15):1959-60.

34. Ward JH. Hierarchial grouping to optimise an objective function. J Am Stat Assoc. 1963:58(301):236-44.

35. Suzuki R, Shimodaira H. Pvclust: an R package for assessing the uncertainty in hierarchical clustering. Bioinformatics. 2006;22(12):1540-2.

36. Falcon S, Gentleman R. Using GOstats to test gene lists for GO term association. Bioinformatics. 2007;23(2):257-8.

37. Martin M, Brase JC, Ruiz A, Prat A, Kronenwett R, Calvo L, et al. Prognostic ability of EndoPredict compared to research-based versions of the PAM50 risk of recurrence (ROR) scores in node-positive, estrogen receptor-positive, and HER2-negative breast cancer. A GEICAM/9906 sub-study. Breast Cancer Res Treat. 2016;156(1):81-9.

38. Paik S, Shak S, Tang G, Kim C, Baker J, Cronin M, et al. A multigene assay to predict recurrence of tamoxifen-treated, node-negative breast cancer. N Engl J Med. 2004;351(27):2817-26.

39. Abramovitz M, Barwick BG, Willis S, Young B, Catzavelos C, Li Z, et al. Molecular characterisation of formalin-fixed paraffin-embedded (FFPE) breast tumour specimens using a custom 512-gene breast cancer bead array-based platform. Br J Cancer. 2011;105(10):1574-81.

40. Paik S, Bryant J, Tan-Chiu E, Romond E, Hiller W, Park K, et al. Real-world performance of HER2 testing-National Surgical Adjuvant Breast and bowel project experience. J Natl Cancer Inst. 2002;94(11):852-4.

41. Andre F, Job B, Dessen P, Tordai A, Michiels S, Liedtke C, et al. Molecular characterization of breast cancer with high-resolution oligonucleotide comparative genomic hybridization array. Clin Cancer Res. 2009;15(2):441-51. 
42. Pierga JY, Reis-Filho JS, Cleator SJ, Dexter T, Mackay A, Simpson P, et al. Microarray-based comparative genomic hybridisation of breast cancer patients receiving neoadjuvant chemotherapy. Br J Cancer. 2007;96(2):341-51.

43. Srinivasan $M$, Sedmak $D$, Jewell $S$. Effect of fixatives and tissue processing on the content and integrity of nucleic acids. Am J Pathol. 2002;161(6):1961-71.

44. Veltman JA, Fridlyand J, Pejavar S, Olshen AB, Korkola JE, DeVries S, et al. Arraybased comparative genomic hybridization for genome-wide screening of DNA copy number in bladder tumors. Cancer Res. 2003;63(11):2872-80.

45. Oosting J, Lips EH, van Eijk R, Eilers PH, Szuhai K, Wijmenga C, et al. Highresolution copy number analysis of paraffin-embedded archival tissue using SNP BeadArrays. Genome Res. 2007;17(3):368-76.

46. Jacobs S, Thompson ER, Nannya Y, Yamamoto G, Pillai R, Ogawa S, et al. Genome-wide, high-resolution detection of copy number, loss of heterozygosity, and genotypes from formalin-fixed, paraffin-embedded tumor tissue using microarrays. Cancer Res. 2007:67(6):2544-51.

47. Thompson ER, Herbert SC, Forrest SM, Campbell IG. Whole genome SNP arrays using DNA derived from formalin-fixed, paraffin-embedded ovarian tumor tissue. Hum Mutat. 2005;26(4):384-9.

48. Roylance R, Gorman P, Harris W, Liebmann R, Barnes D, Hanby A, et al. Comparative genomic hybridization of breast tumors stratified by histological grade reveals new insights into the biological progression of breast cancer. Cancer Res. 1999;59(7):1433-6.

49. Chin SF, Wang Y, Thorne NP, Teschendorff AE, Pinder SE, Vias M, et al. Using array-comparative genomic hybridization to define molecular portraits of primary breast cancers. Oncogene. 2006;26(13):1959-70.

50. Attard G, Cooper CS, de Bono JS. Steroid hormone receptors in prostate cancer: a hard habit to break? Cancer Cell. 2009;16(6):458-62.

51. Chin SF, Wang Y, Thorne NP, Teschendorff AE, Pinder SE, Vias M, et al. Using array-comparative genomic hybridization to define molecular portraits of primary breast cancers. Oncogene. 2007;26(13):1959-70.

52. Farabegoli F, Hermsen MA, Ceccarelli C, Santini D, Weiss MM, Meijer GA, et al. Simultaneous chromosome $1 \mathrm{q}$ gain and $16 \mathrm{q}$ loss is associated with steroid receptor presence and low proliferation in breast carcinoma. Mod Pathol. 2004;17(4):449-55.

53. Cronin M, Pho M, Dutta D, Stephans JC, Shak S, Kiefer MC, et al. Measurement of Gene expression in archival paraffin-embedded tissues: development and performance of a 92-Gene reverse transcriptasepolymerase chain reaction assay. Am J Pathol. 2004;164(1):35-42.

54. Lacroix M, Leclercq G. About GATA3, HNF3A, and XBP1, three genes coexpressed with the oestrogen receptor-[alpha] gene (ESR1) in breast cancer. Mol Cell Endocrinol. 2004;219(1-2):1-7.

55. Wirapati $P$, Sotiriou $C$, Kunkel $S$, Farmer $P$, Pradervand $S$, Haibe-Kains $B$, et al. Meta-analysis of gene expression profiles in breast cancer: toward a unified understanding of breast cancer subtyping and prognosis signatures. Breast Cancer Res. 2008;10(4):R65

56. Hicks J, Krasnitz A, Lakshmi B, Navin NE, Riggs M, Leibu E, et al. Novel patterns of genome rearrangement and their association with survival in breast cancer. Genome Res. 2006;16(12):1465-79.

57. Rouzier R, Perou CM, Symmans WF, Ibrahim N, Cristofanilli M, Anderson K, et al. Breast cancer molecular subtypes respond differently to preoperative chemotherapy. Clin Cancer Res. 2005;11(16):5678-85.

58. Penault-Llorca F, Abrial C, Raoelfils I, Chollet P, Cayre A, Mouret-Reynier $M A$, et al. Changes and predictive and prognostic value of the mitotic index, Ki-67, cyclin D1, and cyclo-oxygenase-2 in 710 operable breast cancer patients treated with neoadjuvant chemotherapy. Oncologist. 2008;13(12):1235-45.

59. Simon RM, Dobbin K. Experimental design of DNA microarray experiments. BioTechniques. 2003;Suppl:16-21.

60. Waldron L, Coller HA, Huttenhower C. Integrative approaches for microarray data analysis. Methods Mol Biol. 2012;802:157-82.

61. Specht K, Harbeck N, Smida J, Annecke K, Reich U, Naehrig J, et al. Expression profiling identifies genes that predict recurrence of breast cancer after adjuvant CMF-based chemotherapy. Breast Cancer Res Treat. 2009;118(1):45-56.

62. Chang JC, Wooten EC, Tsimelzon A, Hilsenbeck SG, Gutierrez MC, Tham Y-L, et al. Patterns of resistance and incomplete response to Docetaxel by Gene expression profiling in breast cancer patients. J Clin Oncol. 2005;23(6):1169-77.

63. Brenton JD, Carey LA, Ahmed AA, Caldas C. Molecular classification and molecular forecasting of breast cancer: ready for clinical application? J Clin Oncol. 2005;23:7350-60.

\section{Submit your next manuscript to BioMed Central and we will help you at every step:}

- We accept pre-submission inquiries

- Our selector tool helps you to find the most relevant journal

- We provide round the clock customer support

- Convenient online submission

- Thorough peer review

- Inclusion in PubMed and all major indexing services

- Maximum visibility for your research

Submit your manuscript at www.biomedcentral.com/submit
Biomed Central 